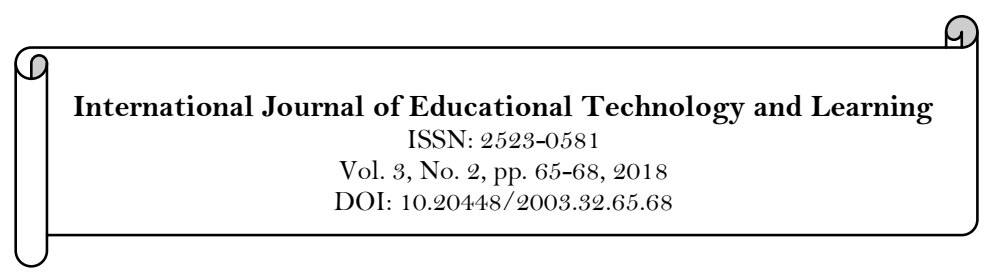

\title{
Using Augmented Reality to Increase Interaction in Online Courses
}

\author{
Sherry Vafa ${ }^{1 s}$ \\ Kayla Sappington ${ }^{2}$ \\ Rita Coombs-Richardson ${ }^{3}$ \\ ${ }^{1,2,3}$ University of Houston - Victoria, USA. \\ ${ }^{1}$ Email:vafas@uhv.edu
}

\begin{abstract}
Augmented reality (AR) is technology that combines virtual reality with the real world in the form of live video imagery that is digitally enhanced with computer-generated graphics (Perdue, 2017). Augmented reality was used in a graduate level distance education course offered in the summer of 2017 to foster interaction. Students enrolled in the course had an opportunity to download and create augmented reality assignments to become familiar with the use of this technology as another tool to communicate and collaborate in online settings. Findings included primarily positive student attitudes regarding the use of AR in the online classroom.
\end{abstract}

Keywords:

Technology adoption

Educational technology

Distance learning

Emerging technology

Augmented reality.

Licensed:

This work is licensed under a

Creative Commons Attribution

4.0 License.

Publisher:

Scientific Publishing Institute

\section{Introduction}

According to Distance Education Enrollment Report 2017 (Allen \& Seaman, 2017) distance education is rapidly growing in higher education. "For each one-year period (2012 to 2013, 2013 to 2014, and 2014 to 2015), the number of distance students at public institutions has shown an increase". Over 6.3 million students are now taking at least one online course (Zinshteyn \& Gordon, 2018). As distance programs grow, there is a need to offer high quality courses to students. One of the challenges for faculty is to provide adequate collaboration, communication, and interaction in distance courses. A quantitative survey research study conducted by Gallop for "Inside Higher Ed" in 2017 collected data from faculty members and digital learning leaders to understand the views and faculty perception on distance teaching experience. The results revealed that $83 \%$ of faculty believed that meaningful interaction is lacking in online courses and - $60 \%$ of faculty disagreed or strongly disagreed that online courses can achieve the same student learning outcomes as face-to-face courses. Faculty members overwhelmingly perceive online instruction to be less effective than inperson classes in interaction with students during class and in reaching at-risk students.

AR was used in an online course to provide an experience for students to download and use an augmented reality app, Aurasma (HP Reveal), as well as have students interact and collaborate by applying the app in their distance learning course.

\section{Literature Review}

Scholars in education and computer science disciplines define Augmented Reality (AR) diversely. Klopfer and Squire (2008) stated that AR is "a situation in which a real-world context is dynamically overlaid with coherent location or context-sensitive virtual information" (p. 205). In this concept, AR provides users with technology-mediated experience where the virtual and real world are blended and user's communication and interactions are augmented (Wu, Lee, Chang, \& Liang, 2013).

According to Rankohi and Waugh (2013) AR is an emergent technology that provides an overview of the real world where details inserted in a computer are superimposed to generate files such as videos, sounds, graphics, digital information or graphics. In a similar vein, El Sayed, Zayed, and Sharawy (2011) defined AR as "the technology of adding virtual objects to real scenes through enabling the addition of missing information in real life" (p. 1045). The technology came in the limelight in the 1960 s when Ivan Sutherland at Harvard 
developed a see-through head-mounted AR display and since then has been modified leading to better and more interactive systems (Rankohi \& Waugh, 2013).

Emerging technologies such as augmented reality and virtual reality have never been more affordable and more intuitive to use. AR is one of the most popular emerging technologies today. Companies such as Target and Vogue use augmented reality in advertisements. Museums and movie theaters use AR technology to provide more information to visitors regarding their exhibits and offerings. AR technologies can also be used in engineering, aerospace, education and entertainment areas (Rankohi \& Waugh, 2013). Several reviews of literature reveal that the use of augmented reality benefits instruction (Billinghurst, 2002; Bujak et al., 2013) and that applications such as DAQRI Elements 4D and Arloon are effective tools to enhance students' learning experience.

The capabilities of AR lead to a mixed reality where real environments and abstract objects coexist to provide a uniquely tailored augment learning experiences for every student (Chen, Liu, Cheng, \& Huang, 2017). Another usage of $\mathrm{AR}$ is with students that have impaired hearing which requires particular technologies to enhance their learning. In a quasi-experiment conducted by Da Silva, Roberto, and Teichrieb (2015) on the impact of ARBlocks in teaching the English language, it was found that the AR tool helped in motivating students and establishing the development of their language skills. The findings are consistent with those of McNair and Green (2016) who measured the level of acceptance of AR books. The AR books had an impact on motivation level which encouraged class engagement and resulted in a positive impact on the student's performance (McNair \& Green, 2016). The enthusiasm of the students also contributed to the perception of this technology and the fact that it complements their personal life in the world of tablets and smartphones.

AR also cuts across different students' needs ranging from kinesthetic, auditory, and tactile learners providing an equal opportunity for education for everyone regardless of their disability (Lee, Yeung, \& Ip, 2016). However, there is the need to analyze both the teachers and the learners when using this technology. Balog and Pribeanu (2010) have shown that perceived usefulness and enjoyment are crucial factors in acceptance of an AR application by the tutors and learners, while the simplicity of using it was not a critical factor for student acceptance. The teachers appreciated the added value of the embedded tools which in turn afforded new opportunities for disseminating instructions to the students. The same tools also allowed the teachers to contemplate the usefulness of these non-traditional literacy experiences in improving student teaching (Casey, 2015).

Bacca, Baldiris, Fabregat, and Graf (2014) led a systematic review of the literature on augmented reality in education by focusing on uses, advantages, limitations, effectiveness, challenges and features of augmented reality in education. They analyzed thirty-two studies between 2003 and 2013 to highlight the research about $\mathrm{AR}$ in education, as well as the trends, future, and opportunities for future studies. One of the significant results from this study was that AR was effective for a better learning performance, learning motivation, student engagement and positive attitudes.

In another meta-analysis review conducted by Radu (2014) 26 publications comparing student learning in AR versus non-AR applications were analyzed and reported on the learning benefits from augmented reality on the following categories: increased content understanding, learning language association, long term memory retention, improved physical performances, improved collaboration, and increased student motivation. Fotaris, Pellas, Kazanidis, and Smith (2017) in a recent systematic review of 17 studies between 2012 and 2017, concluded that AR in education can potentially influence the students' learning in a variety of domains such as skill building and collaboration. This is critical in an on-line course where students are physically separated. AR is an important mechanism to support virtual closeness. The use of augmented reality $(\mathrm{AR})$ in formal education could prove to be a significant factor in future learning environments that include a combination of hardware and software applications (Kerawalla, Luckin, Seljeflot, \& Woolard, 2006). AR could make distant learning more authentic by providing collaboration and communication in an augmented form. Augmented reality has the potential to transform education (Klopfer \& Sheldon, 2010).

AR initiatives have been rapidly increasing in the business world. The global AR and VR market is estimated to witness growth at a CAGR of $85.4 \%$ and $44.5 \%$ respectively over the period of 2016 to 2022 (BIS Research, 2016). AR can similarly be beneficial in education settings; however, as indicated by current literature reviews, there are not many significant studies on how augmented reality can be used for distance learning as an interactive tool to promote collaboration and communication. Additional studies are needed in this prevailing new field.

\section{The Study}

The course selected for the present study was a graduate technology course offered in the summer of 2017. The course was ideal for this case study since it had only 8 enrolled students. One of the goals of the course was to provide students with opportunities to experience the creation of advanced technology learning environments and user experiences as applied to the concept of a technology-based learning.

The course was designed to be interactive and provided students with many opportunities to interact with collaborative tools in the course management software such as wiki, discussion board, messaging and using 
online conference tools. Another tool used to provide more interaction was the use of augmented reality. The instructor created a channel for all students in Aurasma, one of the numerous AR applications. All the students in the course were asked to create a short video at the beginning of the course to introduce themselves and share some information to other students such as their current job and course expectation. Instead of posting their introduction video as an assignment in the discussion board, they were asked to create an "aura" in the Aurasma channel. The Aurasma channel provided another means for students to communicate, collaborate, and interact. The following questions were asked to learn about the effectiveness of this emerging technology to foster interaction in an online course:

1. Did you find value in using AR video in this course?

2. Did the AR foster interaction in the course?

3. From the available Blackboard tools, which interaction tool did you find the most valuable?

4. Why did you find this interaction tool the most valuable?

5. Did you feel isolated during the course?

6. Do you plan to integrate AR into your own classroom?

7. Open-ended comments in regard to use of AR in this course?

8.

\section{Results}

Responses were collected by a survey and phone conference. The results of the study provides insight on students' perception on use of augmented reality applications in distance education courses. The main results indicate that the students were receptive on using AR and found value in AR assignments. More importantly, after exposure to the AR activity, most of them indicated that they plan to integrate AR into their own classrooms. The open-ended question and follow up phone conference revealed positive student attitudes regarding the usability of AR in the classroom.

Some of the responses from phone conference and open-ended questions:

- "Utilizing augmented reality really helped make the content more engaging. I plan on sharing this tool with my students this year."

- "It allowed me to get a better understanding of my classmates and their views on education. That, in turn, allowed me to build a bond with some of my classmates."

- $\quad$ "I feel AR is a unique way to engage students in learning, especially if they are the ones who create it. It teaches videography and layout skills that could be applied to future careers. It would also be valuable for them to see how AR works behind the scenes."

\section{Conclusion and Future Study}

The majority of the study's participants were over 28 years old with a major in instructional technology. They were interested in participating in the study and readily submitted their responses. The small number of participants can be considered as a strength of the study. Each student had the opportunity to work one on one with the instructor to use AR in the course. It was easier to conduct phone interviews to discuss the use of AR in the course. However, a small sample size can also be considered as one of the limitations of this study. Due to the small sample size the findings of this study should not be generalized to a larger population of online students. Results of the study need to be interpreted very carefully. The administration of a structured questionnaire can generate an atypical situation to the respondent. Their responses may be what they wish to attain. Research questions cannot be modified.

This study provided a snapshot of how augmented technology can be used in education. It allowed us to capture a glimpse of a user population although the interpretation may still cause difficulties. Interaction is a legitimate concern in education. This study indicated that the participants eagerly used the technology to interact and collaborate. In addition, all the students found value in using this tool in education. The results of the study, nevertheless, indicated that the level of interaction in this course was increased.

This study is a good beginning for future implementation of AR technology in distance learning. However, in order to assess the true effectiveness of this emerging tool to increase and foster interaction and communication; there is need for additional studies with larger sample sizes and more reliable and valid survey instrument.

\section{References}

Allen, I. E., \& Seaman, J. (2017). Digital learning compass: Distance education enrolment report 2017. Retrieved from http://onlinelearningsurvey.com/reports/digtiallearningcompassenrollment2017.pdf.

Bacca, J., Baldiris, S., Fabregat, R., \& Graf, S. (2014). Augmented reality trends in education: A systematic review of research and applications. Journal of Educational Technology \& Society, 17(4), 133-149.

Balog, A., \& Pribeanu, C. (2010). The role of perceived enjoyment in the students' acceptance of an augmented reality teaching platform: A structural equation modelling approach. Studies in Informatics and Control, 19(3), 319-330.

Billinghurst, M. (2002). Augmented reality in education. New Horizons for Learning, 12(5), 1-5.

BIS Research. (2016). Global augmented reality and virtual reality market - analysis \& forecast, 2016-2022. Retrieved from 
https://bisresearch.com/industry-report/global-augmented-virtual-reality-marketreportforecast.html?gclid=EAIaIQobChMI2ZHHp8zx2QIVl7XACh1Vkw8VEAAYASAAEgJC9fD_BwE.

Bujak, K. R., Radu, I., Catrambone, R., Macintyre, B., Zheng, R., \& Golubski, G. (2013). A psychological perspective on augmented reality in the mathematics classroom. Computers \& Education, 68, 536-544.

Chen, P., Liu, X., Cheng, W., \& Huang, R. (2017). A review of using augmented reality in education from 2011 to 2016. Innovations in smart learning (pp. 13-18). Singapore: Springer.

Da Silva, M. M. O., Roberto, R., \& Teichrieb, V. (2015). Evaluation of augmented reality technology in the English language field. In Brazilian Symposium on Computers in Education, 26(1), 577.

El Sayed, N. A., Zayed, H. H., \& Sharawy, M. I. (2011). ARSC: Augmented reality student card. An augmented reality solution for the education field. Computers \& Education, 56(4), 1045-1061.

Fotaris, P., Pellas, N., Kazanidis, I., \& Smith, P. (2017). Augmented reality game-based applications in primary education. In 11 th European Conference on Games Based Learning (ECGBL). Mini Track on Mixed Reality for Game-Based Learning proceedings. Austria.

Kerawalla, L., Luckin, R., Seljeflot, S., \& Woolard, A. (2006). Making it real”: Exploring the potential of augmented reality for teaching primary school science. Virtual Reality, 1O(3-4), 163-174.

Klopfer, E., \& Sheldon, J. (2010). Augmenting your own reality: Student authoring of science-based augmented reality games. New Directions for Student Leadership, 2010(128), 85-94.

Klopfer, E., \& Squire, K. (2008). Environmental Detectives - the development of an augmented reality platform for environmental simulations. Educational Technology Research and Development, 56(2), 203-228.

Lee, C., Yeung, A. S., \& Ip, T. (2016). Use of computer technology for English language learning: Do learning styles, gender, and age matter? Computer Assisted Language Learning, 5(29), 1035-1051.

McNair, C. L., \& Green, M. (2016). Preservice teachers' perceptions of augmented reality. Literacy Summit Yearbook, 74-81.

Radu, I. (2014). Augmented reality in education: A meta-review and cross-media analysis. Personal and Ubiquitous Computing, 18(6), 1533-1543.

Rankohi, S., \& Waugh, L. (2013). Review and analysis of augmented reality literature for construction industry. Visualization in Engineering, 1(1), 1-18.

Wu, H. K., Lee, S. W. Y., Chang, H. Y., \& Liang, J. C. (2013). Current status, opportunities and challenges of augmented reality in education. Computers \& Education, 62, 41-49.

Zinshteyn, M., \& Gordon, L. (2018). Brown's budget seeks big changes to community college funding and online learning. Retrieved from https://edsource.org/2018/browns-last-budget-seeks-big-changes-to-community-collegefunding-and-online-learning/592452. 